more severe cases fared better than would have been expected on the prognostic index. In one case the initial diagnosis of myocardial infarction was made on acidosis alone. In another case a severe degree of acidosis preceded cardiac arrest.

It would appear that where poor-risk cases require intensive therapy one method suitable for the selection of such cases is by measurement of the base deficit. In this series there is a significant difference in 28-day survival between acidotic and nonacidotic cases. Certainly base deficit appears to be an indication of the severity of the myocardial infarction. Only one case in 17 with a base deficit greater than minus $5 \mathrm{mEq} / 1$. failed to produce complications.

The site of the infarction does not seem to alter the degree of acidosis. In this study the samples were taken on presentation at the hospital. This time varied considerably from the actual onset of infarction (taken as the onset of severe pain). The samples were then grouped into $0-12,12-24,24-48$, and 48-72 hours post-infarction. A significant base deficit measured within the first 12 hours carried a $28 \%$ mortality, within $12-24$ hours a $9 \%$ mortality, and within $24-48$ hours a $5 \%$ mortality.

It must be remembered that there are other causes of metabolic acidosis, such as uraemia and diabetes, and these must be excluded before the whole acidosis is thought to be due to the myocardial infarct. It would also appear reasonable from this study that the correction of the acidosis may improve the prognosis, and a trial is at present in progress to establish whether correction of the acidosis improves prognosis and reduces complications.

\section{Summary}

Fifty cases of acute myocardial infarction have been investigated with respect to the development of metabolic acidosis.

In this series $66 \%$ of such cases developed a significant acidosis.

In a proportion of shocked cases correction with intravenous sodium bicarbonate resulted in a rise in systolic blood-pressure.

Of the 50 patients $13(26 \%)$ died within 28 days. Twelve of the fatal cases in this series showed a significant base deficit, only one being in the non-acidotic group. The non-acidotic patients had a significantly better prognosis.

Measurement of metabolic acidosis may be a useful guide to the degree and severity of acute myocardial infarction. A significant base deficit occurring within 12 hours of infarction carried a $28 \%$ mortality in this series.

I would like to thank Dr. G. R. Royston for permission to study the cases under his care, Dr. J. Collis for statistical work, and Miss V. Spiller for secretarial work.

\section{REFERENCES}

Astrup, P., Jørgensen, K., Andersen, O. S., and Engel, K. (1960). Lancet, 1, 1035.

Harrison, E. M., and Galloon, S. (1965). Brit. F. Anaesth., 37, 13. MacKenzie, G. J., Taylor, S. H., Flenley, D. C., McDonald, A. H., Staunton, H. P., and Donald, K. W. (1964). Lancet, 2, 825.

Peel, A. A. F., Semple, T., Wang, I., Lancaster, W. M., and Dall, J. L. G. (1962). Brit. Heart f., 24, 745 .

\title{
In-vivo Cell Kinetics of a Normal Human Tissue*
}

\author{
GEORGE WIERNIK, $†$ M.D., D.M.R.T.
}

Brit. med. F., 1966, 2, 385-387

Very little is known at present of the cell kinetics in an organized human tissue owing to the ethical difficulties which prevent the application of techniques that have been used in experimental animals. Most of these techniques rely on a substance carrying a radioactive label which is incorporated into the nucleus of the cell at the time of D.N.A. synthesis. Limited studies of the cell kinetics of the human small-intestinal mucosa by the use of tritiated thymidine have been reported (Lipkin, Sherlock, and Bell, 1963 ; MacDonald, Trier, and Everett, 1964 ; Shorter, Moertel, Titus, and Reitemeier, 1964).

The present study has revealed the basic pattern of response to damage of an organized tissue and the repair thereof as it occurs in the human jejunal mucosa. The damage was caused by a dose of $x$-irradiation which affected mainly the crypt epithelial cells ; the dose was insufficient to produce observable effects in the adult epithelial cells on the villi (Quastler, 1959), so that any changes could be considered to be secondary to damage of the crypt epithelial cells. Further, it was thought that irradiation caused non-specific damage to the crypt cells, which form the proliferative compartment of the epithelial cells lining the intestinal mucosa. It has been shown that this dose of irradiation (Wiernik, Shorter, and Creamer, 1962) produced

* This investigation formed part of an M.D. Thesis.

t Assistant Radiotherapist, Department of Radiotherapy, St. Thomas's Hospital, London. Present address: Department of Radiotherapy, Churchill Hospital, Headington, Oxford. similar effects to those of antimitotic drugs (Dustin, 1950 ; Baserga and Morsiani, 1958) in the small intestine of the rat.

\section{Method}

Peroral Biopsy Technique.-The patient in whom this study was conducted was selected from among those whose treatment entailed irradiation of the abdomen when the jejunum was within the area to be treated. Jejunal biopsy, when the pylorus and duodenum have to be negotiated, can be an unpleasant and prolonged procedure which cannot be repeated at short intervals. When direct access to the jejunum becomes possible through prior surgical procedures jejunal biopsy, though no more pleasant, is a rapid procedure, and because of this the patient tolerated it on several occasions. The patient was referred for post-operative irradiation after a Polya-type partial gastrectomy for carcinoma of the stomach. The technique was fully explained to the subject, who was given the option of receiving conventional treatment or of participating in this experimental technique. The patient had fasted for at least two hours before biopsy. Adequate local anaesthesia of the back of the throat was obtained with gargles of $2 \%$ lignocaine hydrochloride, which permitted swallowing of the Crosby peroral jejunal biopsy capsule (Crosby and Kugler, 1957 ; Crosby, 1963). With 
the aid of radiological screen control the capsule was guided through the gastro-jejunal stoma and for some distance along the jejunum to avoid taking the biopsy specimen from a site which was influenced by its proximity to the anastomosis (Creamer, 1964 ; Johnstone and Adams, 1964). The specimen was obtained from the same portion of jejunum on each occasion by the use of markers. The specimen of jejunal mucosa was fixed immediately in Bouin's solution and blocked in wax, and sections were cut at $3 \mu$ and stained with haematoxylin and eosin.

Irradiation Technique.-The patient was treated with a twin-headed Mobaltron cobalt teletherapy unit, which allowed the parallel opposed antero-posterior fields to be irradiated simultaneously. Each of the first three treatments to the jejunal mucosa was of $800 \mathrm{r}$; the final treatment was of $1,000 \mathrm{r}$. The fractionation-that is, the time interval between the individual fractions-was determined by the biopsy appearances.

Method of Cell-counting.-The sections were examined under the light microscope at a magnification of $\times 21$, and an assessment was made of the variations present in the material. A fair cross-section was obtained by counting contiguous structures in an area containing as many variations as possible. All cell counts were done at a magnification of $\times 270$ with a binocular microscope. A hand tally-counter was used at all times. The method of cell-counting was similar to that adopted by Leblond and Stevens (1948), and only nuclei with their greatest diameter in the same plane were counted; this therefore included the epithelial cells, the goblet cells, the Paneth cells, and the rare argentaffin cells. Migrating lymphocytes were not counted. At least three different areas from three or four different sections were used for each count. A minimum of 30 row counts (Wimber and Lamerton, 1963 ; Wiernik, 1966) were averaged to obtain the data for any individual figure. Metaphase mitotic counts were undertaken to minimize the errors involved in estimating mitotic activity (Leblond and Walker, 1956).

\section{Results}

Crypt Epithelial-cell Count.-The crypt epithelial-cell row count in the pretreatment biopsy was accepted as the baseline for evaluation of the serial biopsies. After the dose of irradiation the count diminished gradually for six days (Fig. 1); then
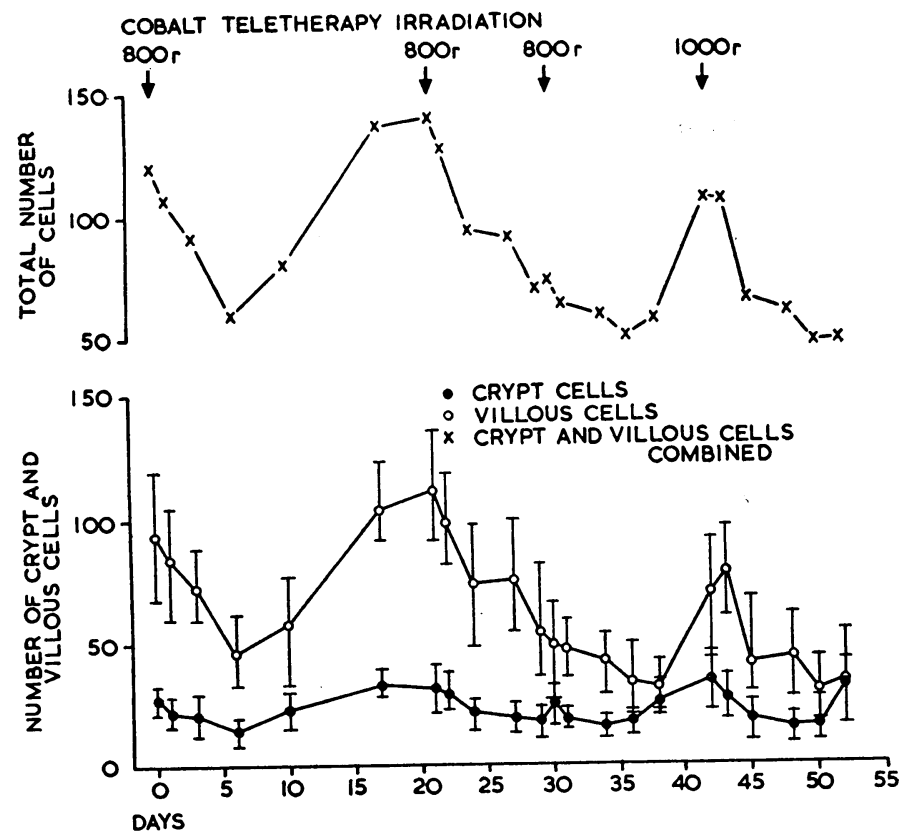

FIG. 1.-Graphs showing the fall and rise in epithelial-cell row counts in the human jejunal mucosa after injury from irradiation. it began to increase, reaching the pretreatment level on about the twelfth day. The row count continued to rise until the seventeenth day, when it was about $20 \%$ greater than the pretreatment level, and then gradually decreased. A similar cellular response to damage was observed in the same patient on four successive occasions (Fig. 2).

Villous Epithelial-cell Count.-The villous epithelial-cell row count reflected the changes in the crypt count both when this was diminishing and when it rose again. There was, however, a lag of 24 to 48 hours between the time that changes were noted in the crypt and when they became apparent on the villus. Thus between the seventeenth and the twenty-first day the crypt count had passed its maximum and was falling, whereas the villous cell count was still rising. The converse is seen between days 29 and 30 , when the crypt count had started to rise, while the villous count was still falling (Fig. 1).

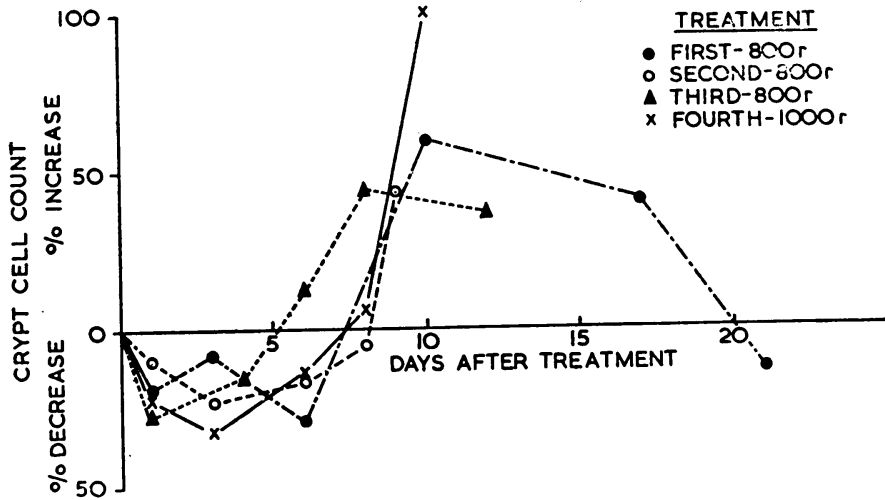

Fig. 2.-Superimposed graphs of changes in the crypt epithelial-cell row counts following four successive incidents of cellular damage showing a similar response on each occasion.

Metaphase Mitotic Index.-This was derived by dividing the metaphase mitotic count in each row of crypt cells by the number of epithelial cells in that row. Mitotic activity was markedly diminished 24 hours after damage by irradiation on each of the four occasions (Fig. 3). There was a small tran-
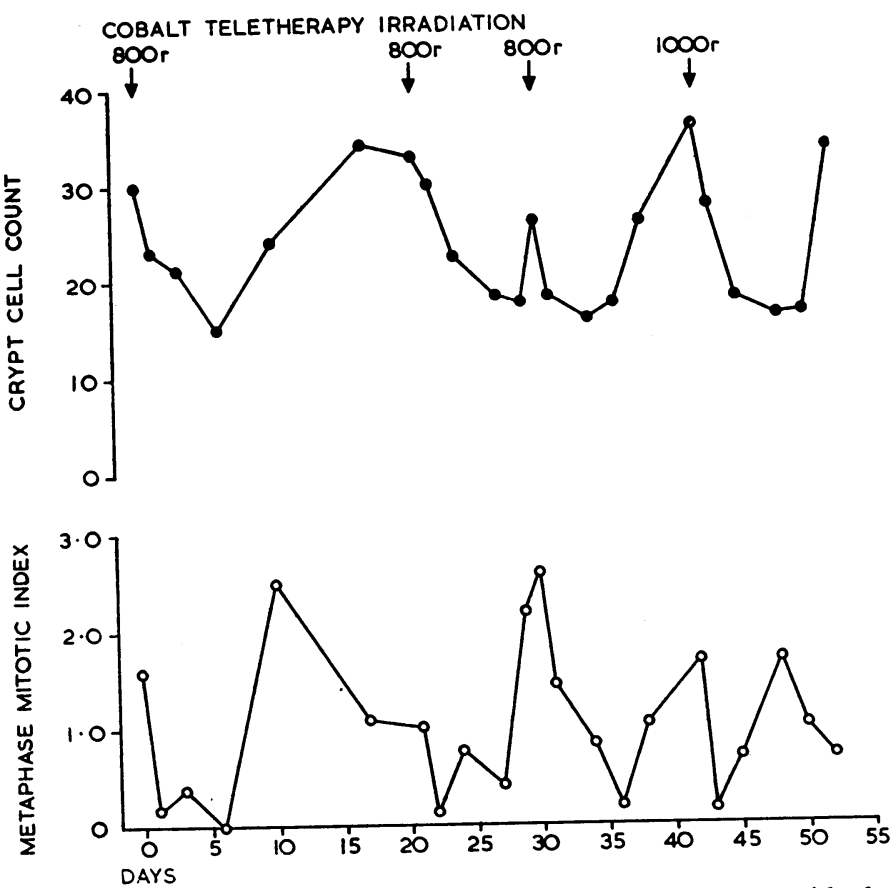

FIG. 3.-Graphs comparing the crypt epithelial-cell row count with the metaphase mitotic index illustrating abortive and sustained mitotic recovery after inhibition. 
sient rise in the index between the third and the fifth day which was followed, after a fall, by a much more pronounced rise, leading to a value $60 \%$ greater than the pre-treatment index. There was a delay of between 24 and 48 hours between changes in the mitotic index and the rise or fall in the crypt epithelialcell count, so that the index had fallen already between the tenth and seventeenth days, while the cell count was still rising, whereas the index rose between the twenty-seventh and twentyninth days, while the cell count fell.

\section{Discussion}

When an organized tissue such as the mucosa of the human jejunum is damaged by $x$-irradiation mitotic activity, which under normal circumstances is confined to the crypt, is markedly diminished. The drop noted in the crypt epithelial-cell row count after one day is probably due to a combination of the disintegration of cells lethally injured by the radiation and to continued migration on to the villus of cells which have differentiated. The fall in the villous epithelial-cell count after one day is thought to be the result of continued migration of the cells, leading to a larger number being lost from the extrusion zone than are being replaced by migration from the crypt.

A lag period of approximately 24 to 48 hours has been observed, both after inhibition of mitotic activity and after its sustained recovery, between each of the three criteria studiednamely, the metaphase mitotic index, the crypt, and villous epithelial-cell row counts. From this it may be deduced that the number of epithelial cells is dependent on the mitotic activity in the crypt cells and that migration of epithelial cells takes place from the crypt on to the villus.

The transitory rise in the metaphase mitotic index which was noted three days after mitotic inhibition probably corresponds to the abortive mitotic recovery observed in the intestinal mucosa of the rat (Williams, Toal, White, and Carpenter, 1958), as this burst of mitotic activity was not followed by any evidence of an increase in the number of crypt epithelial cells; on the contrary, the crypt count diminished at a steady rate throughout this period, whereas approximately 24 hours after sustained recovery of the metaphase mitotic count an increase in the crypt epithelial-cell count becomes apparent (Fig. 3).

When recovery in the crypt epithelial-cell row count takes place the number of cells rises to above pre-treatment level, and this is referred to as the "overshoot" phenomenon. No record of this in a human tissue has been traced, though it has been reported following irradiation of tissue cultures (Canti and Spear, 1929) and of the intestine of experimental animals (Friedman and Warren, 1942 ; Knowlton and Hempelmann, 1949 ; Williams et al., 1958 ; Hendrickson and SkyPeck, 1963). During the overshoot period mitotic activity can be observed in the epithelial cells lining the base of the villus ; which suggests that at this time cells are able to leave the crypt prior to differentiation.

The observations in this report are based on serial biopsies from only one patient, but their validity is regarded as proved by the demonstration of the same sequence of events, both qualitatively and quantitatively, following four separate incidents of damage by irradiation. This is shown more clearly when the data are plotted graphically and superimposed (Fig. 2).

\section{Summary}

The cell kinetics in an organized human tissue have been revealed by studying the response to damage and the repair process in the epithelial cells lining the jejunal mucosa. Damage from irradiation is followed by a gradual fall in the number of epithelial cells lining both the crypt and the villus. On about the third day there is evidence of abortive mitotic recovery. After the sixth day sustained mitotic recovery occurs, followed some 24 hours later by a gradual repopulation of the crypt and a further 24 hours later by an increase in the villous epithelial-cell count. The initial number of cells in each compartment is reached on the twelfth and the fifteenth day respectively, after which the number continues to increase to about $20 \%$ above the normal value before falling once more to that level. This has been termed the overshoot phenomenon.

I am indebted to Dr. J. A. C. Fleming, Physician-in-charge, Department of Radiotherapy, for constant help and encouragement; to Professor R. C. Curran and Dr. B. Creamer for the provision of facilities which enabled me to undertake this study ; to Mrs. Dorothy Barton for technical assistance; and to the Medical Research Council for a personal grant as well as for the salary of a technician.

\section{REFERENCES}

Baserga, A., and Morsiani, M. (1958). Rass. med. cult., 35, 208. Canti, R. G., and Spear, F. G. (1929). Proc. roy. Soc. B, 105, 93. Creamer, B. (1964). Brit. med. F., 2, 1373.

Crosby, W. H. (1963). Lancet, 1, 500.

- and Kugler, H. W. (1957). Amer. F. dig. Dis., 2, 236.

Dustin, P., jun. (1950). Rev. Hémat., 5, 603.

Friedman, N. B., and Warren, S. (1942). Arch. Path., 33, 326.

Hendrickson, F. R., and SkyPeck, H. (1963). Radiology, 80, 244.

Johnstone, J. M., and Adams, J. F. (1964). Gut, 5, 60.

Knowlton, N. P., jun., and Hempelmann, L. H. (1949). f. cell. comp. Physiol., 33,73.

Leblond, C. P., and Stevens, C. E. (1948). Anat. Rec., 100, 357

- and Walker, B. E. (1956). Physiol. Rev., 36, 255.

Lipkin, M., Sherlock, P., and Bell, B. (1963). Gastroenterology, 45, 721.

MacDonald, W. C., Trier, J. S., and Everett, N. B. (1964). Ibid., 46, 405

Quastler, H. (1959). Radiology, 73, 161.

Shorter, R. G., Moertel, C. G., Titus, J. L., and Reitemeier, R. J. (1964). Amer. F. dig. Dis., 9, 760 .

Wiernik, G. (1966). Brit. f. Radiol., 39, 272.

- Shorter, R. G., and Creamer, B. (1962). Gut, 3, 26

Williams, R. B., jun., Toal, J. N., White, J., and Carpenter, H. M. (1958), 7. nat. Cancer Inst., 21, 17.

Wimber, D. R., and Lamerton, L. F. (1963). Radiat. Res., 18, 137. 